\title{
Special Thematic Issue on: International Interactions and Activities of University-Based Technology Entrepreneurship
}

\author{
Hamid Etemad ${ }^{1}$
}

Published online: 30 August 2016

(C) Springer Science+Business Media New York 2016

The Journal of International Entrepreneurship (JIEN) is pleased to present this special thematic issue on the broad theme of international entrepreneurship in universities, as the university-based entrepreneurship could be one of the important contributing principals to the field of International Entrepreneurship (IE) as a whole. The present thematic issue is guest-edited by Professors Natasha Evers (National University of Ireland at Galway, Ireland), James A. Cunningham (Northumbria University, Newcastle upon Tyne, UK), and Thomas Hoholm (BI Norwegian Business School, Oslo, Norway); and it is the result of an open call for papers that appeared more than a year ago on JIEN's website (http://www.springer.com/business $\% 26$ +management/entrepreneurship/journal/10843).

I am delighted that this issue meets and exceeds the JIEN's strict standards. All papers submitted to the journal for this special issue were subjected to the journal's routine rigorous double-blind reviews and benefited from the valuable comments of the Journal's distinguished panel of reviewers and the three guest editors. This thematic issue further gained from the guest-editors' recent book entitled Technology Entrepreneurship - Bringing Innovation to the Marketplace published by Palgrave-Macmillan, London.

The guest-editors' introductory editorial is descriptive, insightful and needs no further commentary. However and in light of the long overdue need for exploring entrepreneurial orientation in the post-secondary higher educational institution, I would like to highlight some advancing developments, which will have significant impacts on entrepreneurship in general and on the university-based international entrepreneurship in particular. Most of these developments are knowledge- and technology-intensive, attracting massive venture capital investment, and are internationalizing rapidly to the

Hamid Etemad

hamid.etemad@mcgill.ca

1 McGill University, Montreal, QC, Canada 
far corners of the world, with potential impact on similar entrepreneurial initiatives aspiring to internationalize, including university-based ventures.

As the theme of this special issue indicates, the seven papers in the issue have focused on different aspects of the topic from the general perspective of universityrelated entrepreneurship and have collectively pointed to the emergence of three significant, related, and shared sub-themes-context, emergence, and actors. This preface will highlight a few issues concerning entrepreneurship (or international entrepreneurship) emanating from the general university context, before adopting a perspective differing from, but supportive of, the subject matter of this issue in the balance of this article.

University Knowledge-Based Entrepreneurship The research-led knowledge creation has unequivocally been the raison d'étre of progressive universities. However, the practical potency of such research and the commercial value of potential outputs associated with such cutting-edge knowledge are not as yet clear. Although this is a generally perceived view, there are most notably key exceptions - some universitybased knowledge has served mankind well-beyond expectations. The university-based medical sciences provide vivid examples, where a combination of biological and medical knowledge, bio-engineering capabilities, and clinical or professional expertise, among many other pure and applied sciences, converges to discover and offer a range of potential remedies, or solutions, for human health problems. Subsequent experimental and clinical trials, conducted under strict protocols and standards, identify the most effective procedures that would eventually become routine remedial solutions for the original family of health-related problem(s). The history of medical discoveries, innovations, and effective remedial solutions has not only vastly improved upon the state of the patients' health care but also extended health-care improvements within the reach of masses beyond local origins and national boundaries, with the ultimate benefit to humanity. The noteworthy point here is that clinics and hospitals provide the context for the real health-related problems to attract the immediate attention of clinicians and physician who are in the position to devise solutions for those problems and their broader applications regardless of the initial source. The university-based, or corporate $\mathrm{R} \& \mathrm{D}$, has subsequently created the potential remedies for use beyond the original clinics, hospitals, and patients, mostly through commercialization of solutions in the form of new medication or more effective medical procedures. The presence of such effective experience in the university context strongly suggests emulation of both the context (where the problem can meet those who can create the solution) and the possibility of gaining experiential knowledge beyond medical sciences extended to other disciplines within and outside university, through their international medical sciences and other networks. Stated briefly and differently, the health-care system has provided an effective and functional context for "the problem" and agents capable of offering "solutions" to meet and interact to enable the eventual discoveries for enacting a range of potential solutions, from which the most effective ones are ultimately adopted. When such meetings and interactions, between the "problem" and the "solution-agents," are structurally impossible, the local, national, and international health-related institutions, such as the Ministries of Health or the World Health Organizations (WHO), can step in to chart a path towards finding a solution as quickly as possible. 
Back to the Entrepreneurship in the University Context The advanced universitybased research generates pure and applied knowledge and solutions that result in cutting-edge publications. Some of these publications are so advanced and complex for many to decipher and realize their relations with prevailing problems in the real world. Generally, there is a need for relating such advances (and their corresponding patents) to the existing, potential or incipient, problems to bring the corresponding opportunities within entrepreneurial sight and motivate a path towards their commercialization.

Advancing the state of knowledge (and education) is the principal university mission, while commercialization is not; and well-trained scientists are engaged to accomplish this mission. As a result, university-based R\&D generates much scientific intellectual property (IP) and many associated patents, some of which do not readily connect with the binding and immediate societal needs and problems, as alluded to earlier. Consequently, aspiring entrepreneurs are likely to fail in seeing those advances and discoveries as the seed of opportunities in order to identify their potential, or real, applications and to enact a start-up for bringing them to the market place. Neither are university scientists well-trained to meet the complex challenges of searching for marketable applications and take the entrepreneurial steps for their commercialization nor are they prepared to face the transition and the possible conflicts between the university-based and entrepreneurial careers, mostly outside the university and in the corporate and private sector. Such a transition is not easy under the best of circumstances. However, some progressive corporate institutions and public universities have already begun experimentation for smoothing the transition to foster more effective commercialization of university-based knowledge and technology, which suggests that universities can emulate and initiate similar initiatives (e.g., the successful "Biodesign Model" at Stanford University and the "BioInnovate Programme" of the National University of Ireland, Galway, following Stanford's lead).

Except for a small breed of scientists-turned entrepreneurs, who foresaw the future commercial application of their knowledge and technology earlier on and prepared for their eventual career transition, the two career paths remain on the two sides of a divide, if not a chasm. Yet, some aspired entrepreneurs, cognizant of entrepreneurial opportunities associated with the university-based knowledge and technology for generating income, wealth, and employment, could succeed in bridging the divide over time; but systematic and wide-spread bridging are yet difficult to find. Even in the boundary-less world of science, such bridge-building efforts have proven to be difficult and have not attracted the necessary attention of either side of the divide. For instance, both the university-based scientist and entrepreneurial agent live in the comfortable isolation of their respective quarters; and it is not yet clear as to how and when such bridges will be built on a larger scale. Furthermore and given the advanced state of university-based knowledge and cutting-edge intellectual properties, the question of why all such knowledge is not yet benefiting humanity through their commercialization by international entrepreneurs remains. Similarly, who should be charged with the responsibility of building such bridges for the benefit of masses or for solving the gripping world problems? The scope of this preface does not allow for developing answers; but it will attempt to identify certain milestones within the landscape of this thematic issue for building bridges to connect across the above divides in the hope of suggesting feasible pathways towards potential solutions. 
In line with my earlier suggestion of the need for interaction across the various divides and especially among the context, emergence, and actors (mentioned as subthemes of the issue in the guest-editors' editorial article), the above discussion and research suggest that something is amiss: either one of the expected three principal parts is missing in action or not interacting with others. Consequently, the vital interaction between the parts has become dysfunctional. In the context of university-based entrepreneurship, the most likely missing agent is the entrepreneur or the university-based, or university-oriented, entrepreneurial agent. Such "agents" would routinely search for, and identify, the value of the raw opportunity, at times embedded, implicit or even tacit in the university environment, in order to build an appropriate context within, or outside, university for capitalizing on those not-so-apparent value(s) and transforming it (them) to real and objective opportunity. If activated, such systematic interactions between the agents (the missing actor), the actual knowledge creators (scientists), and their university support system could result in the emergence of a start-up entrepreneurial firm for commercialization. The transformation and the transition from the university-based knowledge to a tangible and objective opportunity to form the basis for commercialization might be a rocky road; but it is not an unfamiliar path to the university-based scholars and authorities (as exemplified by the brief interaction among the principal agents in medical clinics and hospitals). Under conducive conditions, such entrepreneurs and entrepreneurial firms are more likely to emerge from outside the university environment (as highlighted, for example, by Franco-Leal et al. in this Issue). However, universities could adopt curricular and policy steps to not only generate such entrepreneurs from within but also to enable them to explore the intersection between university-based new knowledge (and technology) and their potential for worldwide commercialization. Undoubtedly, such entrepreneurial explorations would pave the way for the emergence of iconic international entrepreneurs that the youth of the world would aspire to emulate. The pressing question for the universities, and the field of international entrepreneurship by a logical extension, is how to grow such internationally oriented entrepreneurs from within the university borders, while students are in the educational stream? Similarly, how graduates and alumni could be attracted back to the university environment for exposure to complementary disciplines for bridging across disciplines? Such bridging could easily instill confidence and enrich their capabilities for capitalizing on the nexus of the new knowledge, technology, and market potential(s) through boundary-less entrepreneurship (or international entrepreneurship). Reaching such a nexus would require a curriculum of International Entrepreneurship at the intersections of Entrepreneurship, International Business Strategy and Marketing in the Management discipline with each extending certain pathways into the sciences from which the new knowledge and technology had emanated. Aside from further enabling university-based entrepreneurship, such bridging across related disciples will better prepare graduates for the challenges of the real world.

Notwithstanding the salient need for identifying strategies for instituting interactive integration across disciplines to avoid such potential chasms, as alluded earlier, further discussion is far beyond the scope of this preface. However, it would suffice to suggest that integrative arrangement is within universities' easy reach. For example, a joint Engineering and Management curricula in technology-centric entrepreneurship programs, and institutes, charged to bridge across disciplines, has been already tried in the university context and is bearing fruits already. The recent Sutardja Center for 
Entrepreneurship and Technology at the University of California at Berkeley (http://scet.berkeley.edu/) is an excellent example, which is expected to integrate across related disciplines. As for structural institutions bridging the disciplines and Faculties interested in responding to markets-in-need, assisting corporate agents seeking solutions to solve their problems, or even those who are searching for commercialization opportunities, the professors and graduates of the integrated programs could facilitate and even foster commercialization of the wealth of university-based intellectual property much easier and faster than otherwise. Such commercialization can also further contribute to strengthening the universitycorporate collaboration and partnership. Given the decaying nature of most knowledge and the emergence of rapidly internationalizing younger enterprises, such as "platform enterprises," briefly discussed below, time, timing, and speed of developments have assumed critical importance: cutting-edge intellectual property could not be relegated to archives waiting for their time to arrive. They need to be deployed in a timely fashion.

The scholars of ecosystems (e.g., Etzkowitz 2008) go beyond the mere universitycorporate collaboration and suggest that a triple helix ecosystem, comprised of three principal partners - the university, the corporate sector, and the government, is necessary for the long-term success in the knowledge and technology-intensive societies. Our own in depth and ongoing research on high growth and rapidly internationalizing firms (Keen and Etemad 2011b and 2012, Etemad and Wu 2013) further suggests that a functional support network needs to be added to the helical integrated, interactive, and collaborative arrangements among the above mentioned three agents. Such network support system should also include the angle community and the venture capital investors, as they are equally necessary for ensuring firms' growth beyond the early start-up stages. The recent university, corporate, and government partnership and joint sponsorship of regional industrial clusters in Scandinavia also serve as examples of such facilitating interaction and integration in most, if not all, functions of the cluster value chain and the growth of its membership. Similarly, university-based, or university-supported, incubators and accelerators are equally functional options for integrating across the necessary functions and bridging across institutions at relatively smaller scales and for the commercialization of more specialized family of goods and services. It is not surprising that such incubators are slowly appearing in progressive science and technology-oriented university campuses. The noteworthy caveat is that the ultimate success of such incubators is based on the full support of the university(ies) and other relevant corporate and industry support networks.

In contrast to university-based clinics and hospitals that have the two sides of problem-solution equation in sight and within reach, most corporate $\mathrm{R} \& \mathrm{D}$, and even public research centers, need to address existing problems, as well as identify a family of potential future problems, to justify expenditures of precious time and corporate efforts for finding solutions for those problems. Similarly, most entrepreneurs identify opportunities and validate their market viability before spending their entrepreneurial capital (Keen and Etemad 2011a) (e.g., funds, time, social capital) on uncertain market potentials. On the other side of the ledger, there have been visionary entrepreneurs and innovators realizing their entrepreneurial or innovative dreams (e.g., Sir Richard Branson of Virgin Corporate Family, Jeff Bezos of Amazon.com, Elon Musk of Tesla Motors, Sir James Dyson founder of Dyson Vacuum Cleaners, among many others) in highly uncertain markets. It appears that they had set their minds on creating 
a supportive environment, if not an enabling ecosystem, to nurture and sustain their nascent firm for materializing their dreams. Unfortunately, the annals of investment are equally replete with unsuccessful and pandemic of ventures whose time, buyers, suppliers, and support systems had not yet materialized. The so called Dot.Com bubble of the turn-of-the-century serves as a reminder. In short, the entrepreneurial or innovative powers behind iconic firms have provided for most influential aspects of their initially feeble firms to reach successful maturity over the firm's life cycle that have usually extended far beyond the short-term desire for generating profits. Consequently, such firms have been both successful and also disruptive to the legacy industries, which they have pushed out into the sunset, while stepping into their own bright sunrise awaiting them.

In the past, the disruptive nature of Schumpeterian firms has been brought to public attention in highlighting the strong impact of new knowledge and technology as the basis of commercialized innovative and disruptive goods and services. Regardless of where they originate - e.g., from the internal corporate R\&D laboratories, universitybased research, national research centers, $R \& D$ at public institutions, or targeted projects funded by private and public partnership (PPP), knowledge-based entrepreneurship has assumed an influential role nationally and internationally. With the increasing removal of barriers to mobility across countries, international ventures impact competition on practically all markets; and also, the rapid emergence of born global firms from emerging economies indicates that knowledge-based international entrepreneurship neither is bounded by borders and origins nor time. This discussion leads us to the emergence of Platform Enterprises that have already begun to reshape the nature of context, emergence, and actors, discussed earlier.

A Glance at Recent Disruptive Developments As hinted above, we are witnessing the rapid growth, internationalization, and strong disruptive power of knowledge, technology, and information-intensive institutions, such as Air $B \& B$ (established in USA in 2008), Ali Baba (China-1999), Amazon (USA-1999), Baidu (China-2000), Criteo (France-2005), Facebook (USA-2004), Flipkart (India-2007), Garena (Singapore -2009), Google (USA-1998), King.Com (Sweden/UK-2003), Naspers (South Africa - 1915), Shazam (UK-1999), Twitter (USA-2006), Uber Taxi (USA2010), and Xiaomi (China-2010), among many others, that have responded to the desires of the ultimate buyers worldwide for incrementally higher values in timely offerings (usually called "on-demand"). Such desires have been present for millennia, and entrepreneurs recognizing the associated opportunities have fulfilled those incipient needs and wants at the time in their own ways. They have consequently prospered from offering incrementally higher values in a timely fashion and also satisfying social functions at the same time.

The history of entrepreneurship, however, has not witnessed the emergence of the recent phenomenon involving the hurried perception of time, timing, and time-related aspects (Etemad and $\mathrm{Wu} 2013$ ) in entrepreneurship, including speed, that are contributing to the rapid internationalization and high growth of contemporary entrepreneurs and young entrepreneurial start-ups that offer higher perceived values to the ultimate buyers than their entrenched and older competitors, and thereby disrupting the old and established routines. As a result, they threaten the latter's survival and disrupts their industry customary practices so quickly. The question before us is, therefore, how such firms have 
managed to accomplish so much in such neck-breaking speeds and what will be their impact on nascent entrepreneurship, including those emanating from universities? The partial answer is likely to be complex and multi-faceted and include, for example, the following: (i) high entrepreneurial orientation and foresight, (ii) rapid commercialization of enabling knowledge and technologies, including information and communication technologies (ICTs) and internet-based capabilities (IBCs), in providing support systems for their operations, (iii) rapid transformation of just-acquired information (mostly offered voluntarily by buyers and suppliers) into operating knowledge and capabilities for delivering higher valued good and services, (iv) responding to individual buyers' ondemand wishes in timely fashion at reasonable prices, (v) accomplishing the local tasks through their expanding local (foreign) network of capable suppliers, and (vi) improving upon the quality of their tailor-made portfolio of goods and services based on continuous feedback from buyers and suppliers over time.

A Question of Time and Timing? A few aspects of the above operations are germane to the theme of this special thematic issue, including (i) the indispensable role of entrepreneurs in starting-up dynamic young firms in opportune time, (ii) the enabling influence of new knowledge and technology capable of contributing highly, (iii) the importance of time, timing, and speed in the rapid deployment of such new knowledge and technologies, and importantly, (iv) the investment and venture capital communities' timely support for these initiatives' rapid internationalization and continued high growth. The earlier discussion pointed to circumstances that would stimulate internationally oriented entrepreneurship in deploying university-based knowledge and technology, but never before have time and timing played such important roles. Time pressure comes from all sides: entrepreneurs fearing the replication of their ideas and concepts, investors' desiring quicker returns, suppliers' need for larger scales, among others. Consider the case of Air B\&B as an example. In less than 10 years (established in 2008 in San FranciscoBay Area, CA), Air B\&B has developed an impressive presence in the far corners of the world with more than 1,500,000 listings of lodging establishments for shortterm rentals in 34,000 cities of 190 countries. The largest international hotel chain of the world, the Hiltons and Continental Hotels, dwarfs in comparison with Air $\mathrm{B} \& \mathrm{~B}$ size, diverse offerings, and the perceived higher value of such offerings. More importantly, the convenience and timely aspect-e.g., arranging a booking for a short-term rental is as easy and as quick as a typical search and selection on Air B\&B's app on one's smart phone, which saves the person time and money and offers unique features that hotels are incapable of offering at reasonable costs and in a timely fashion. Although operating in somewhat legal gray zone in some environments, Air B\&B has established new expectations and performance standards and has had a highly disruptive impact on the traditional lodging industry worldwide without owning or managing local establishments. It is not surprising that the market valuation of Air B\&B is exceeding \$25 billion and is still increasing. The massive first mover advantages of Air B\&B will be very difficult for young startups to ignore, pointing further to the impact of time and timing. As a result, the university-based entrepreneurs need to pay serious attention to the impact of time, timing, and speed of their entrepreneurial initiatives and the support system needs to be also supportive of their time and timing concerns. 
In addition to the influence of highly committed entrepreneurs and supportive investors, the enlisting of an active and supportive network of collaborators, to supply goods and services in their foreign local environments, has proven to be essential to rapid internationalization and high growth of internationalizing young enterprises (e.g., Air B\&B's local lodging establishments made its meteoric rise possible). Although most university-based scholars have a relatively large scholarly network of collaborating researchers, they are not commercially or entrepreneurially oriented. The prior establishment of such capable support network is among the areas in need of further development along with early commercialization efforts if university-based start-ups were to grow rapidly nationally and globally. Furthermore, universities could inform their international alumni of their potential roles and possibly entice their international networks to facilitate, and hopefully foster, faster development of local service providers in their regions and beyond. Not many other local institutions have as large a network of international alumni as that of internationally oriented universities that can be readily leveraged for internationalization of university-based knowledge and technology initiatives.

Although the university-based international entrepreneurship has been the focal point of the current thematic issue and this preface, the arguments presented in this special issue should be equally germane to other institutions creating new knowledge and technologies, including national research institutions and even private sector corporate R\&D establishments. In summary and regardless of the size and the nature of creative work, their resulting new knowledge and technology can benefit the society at large if it is entrepreneurially and internationally commercialized. The journal encourages scholarly research on the full life-span of idea-to-market cycles internationally and is prepared to receive proposals for thematic issues with pertinent topics and themes with varying scopes of coverage exploring the frontier issues and problems addressed in this issue. Such proposals can be directed to the journal's editorial office or to the editor's attention at hamid.etemad@mcgill.ca for immediate consideration.

Hamid Etemad, Ph.D.

Montreal, Canada

\section{References}

Etemad H, Wu P-C (2013) Revisiting aspects of born globals: young Canadian SMEs growing rapidly and becoming born globals. In: Etemad H (ed) Current issues in international entrepreneurship. Edward Elgar Publishing Ltd., Northampton and Cheltenham, pp. 13-37

Etzkowitz H (2008) The triple helix: university-industry-government innovation in action. Routledge, New York, NY

Keen C, Etemad, H. (2011a). The impact of entrepreneurial capital and rapidly growing firms: The Canadian example, International Journal of Entrepreneurship and Small Business, 12 (3);273-289.

Keen CH, Etemad H (2011b) Rapidly-growing firms and their main characteristics: a longitudinal study from United States. International Journal of Entrepreneurial Venturing 3(4):344-358

Keen CH, Etemad H (2012) Rapid-growth and rapid internationalization of smaller enterprises from Canada. Manag Decis 50(4):569-590 